Editorial

\title{
Territories in Time: Mapping Palimpsest Horizons
}

\author{
Chiara Cavalieri ${ }^{1, *}$ and Elena Cogato Lanza ${ }^{2}$ \\ ${ }^{1}$ SST/LOCI-Faculté d'architecture, d'ingénierie architecturale, d'urbanisme, UCLouvain, 1348 Louvain-la-Neuve, Belgium; \\ E-Mail: chiara.cavalieri@uclouvain.be \\ ${ }^{2}$ LAB-U ENAC, EPFL-École polytechnique fédérale de Lausanne, 1015 Lausanne, Switzerland; \\ E-Mail: elena.cogatolanza@epfl.ch \\ * Corresponding author
}

Submitted: 22 June 2020 | Published: 30 June 2020

\begin{abstract}
In the early 80s André Corboz, in describing the territory as being the result of slow and long-term processes involving multiple transformations, implicitly declares the onset of a new paradigm for understanding cities and territories: a new gaze attentive to the chronological dimension of spaces, aware of the long history of places, interested in that ensemble of signs, traces and voids so tangible, and yet ignored by the paradigm of tabula rasa. To describe this complexity, Corboz proposes the metaphor of territory as palimpsest: A palimpsest is a two-dimensional writing board bearing a three-dimensional matrix of signs, which, as a metaphor, allows for a contextual, four-dimensional apprehension of territory, portraying space in its chronological evolution. This text re-contextualizes the notion of palimpsest-both as a methodological and a theoretical question-in the light of two main conceptual 'shifts': the 'territorial turn,' which increased interest among different disciplines, projects, and policies for the dimension of cities as territory, and the 'digital turn,' namely the rapid evolution of data recording, archiving, and mapping technologies.
\end{abstract}

\section{Keywords}

city-territory; digital transition; mapping; mapping time; palimpsest; territorial turn

\section{Issue}

This editorial is part of the issue "Territories in Time: Mapping Palimpsest Horizons" edited by Chiara Cavalieri (UCLouvain, Belgium) and Elena Cogato Lanza (EPFL, Switzerland).

(C) 2020 by the authors; licensee Cogitatio (Lisbon, Portugal). This article is licensed under a Creative Commons Attribution 4.0 International License (CC BY).

\section{A 'Territorial Turn'}

The essay "Le Territoire Comme Palimpseste," published by the Swiss historian of architecture and urbanism André Corboz (1983), marks a decisive step in what can be called a 'territorial turn.' The text begins by recording an increasing enthusiasm for the theme of territory among a broad cohort of disciplines including, political science, geology, topography, planning, zoology, and cultural history. At the same time, the incredible success of exhibitions such as "Cartes et Figures de la Terre" (organised in Paris, Centre Pompidou, in 1980, no less successful than an exhibition of Impressionist paintings), and the broadening territorial scale of public policies, allow Corboz to conclude that a new "horizon of reference" (Corboz, 1983, p. 15)-a new paradigm-is emerging. A horizon that Corboz sees as an opportunity to definitively overcome the city-countryside opposition inherited from the industrial revolution-an expression of the political and cultural power of the cityin favour of an apprehension of the urban as a larger territorial condition. This leads to a shift in perspective, whereby, with the territory as the unit of measurement of human phenomena, it is now the city-territory that must be referred to when designating the geography of the urban. Now, in Corboz's 1983 essay, the notion of palimpsest enters the scene after a long and dense premise, in order to describe the territory as the outcome of a slow and long-term process involving multiple transformations, to deal with the evolutionary history of 
places, and to stress space as a conglomerate of signs, traces, and voids-so real, and yet altogether ignored in the field of planning, dominated by the paradigm of tabula rasa. In addition, by choosing the metaphor of the palimpsest over the more classical, that of archaeological sedimentation, Corboz not only aligns himself with but goes beyond that 'reclamation of the past' as pursued by the post-modern designers and modern critical theoreticians (Huet, 1986; Rossi, 1966; Rowe \& Koetter, 1978). Only one year after the publication of Gerard Genette's (1982) Palimpsestes: La Littérature au Second Degré, that theorized the palimpsest as a metaphor for the thickness of literature texts, the same metaphor allows Corboz to theorize the territory as a thick blackboard upon which society can write-trace, erase, and ultimately re-tracenew chapters of its urban transformation. The quantity of writing finds its own echo in the sheer number of possible readings. A palimpsest is indeed a two-dimensional writing board carrying a three-dimensional matrix of signs, inscriptions, and texts; as a metaphor, it allows a contextual, four-dimensional apprehension of territory, portraying space in its chronological evolution (Marot, 2013). Finally, such a contextual, four-dimensional apprehension of territory, conceived in its chronological evolution, does not imply that space needs to be read as an incremental accumulation of traces, but rather, and most importantly, as a selective process, through multiple erasures. The metaphor of the palimpsest has disclosed an enormous potential for architectural, urban, and cultural studies, design, and planning (either theory and practice); the infinite quotations of André Corboz's seminal essay in scientific papers and in educational activities are the most visible demonstration. Nevertheless, a precise understanding of Corboz's theoretical proposal cannot help but considering its first, original mapping prototype, that is to say, the Atlas du Territoire Genevois, published by the Canton of Geneva in 1993 (Léveillé, Cassani, \& Mayor, 1993). Realised under the coordination of Léveillé (formerly Corboz's teaching assistant at the University of Montréal, where he taught from 1967 to 1980) the atlas performs a corpus of mapping comparisons between two types of cadastre (the Napoleonic and the federal) through three historical thresholds (about 170 years far): the Napoleonic cadastre (1806-1818), the Plan d'Ensemble du Territoire Genevois (1935-1959), and the contemporary Plan d'Ensemble (1991).

Based on an extremely simple mapping legend (parcel, building, road, vegetation, hydrography, and topography) the comparisons between the three historical thresholds identify single-elements transformations over time-what has been added, what has been transformed, and what has been erased. The transformations are then classified according to three main categories: permanence, persistence, and disappearance (Figure 1). The shift from the complexity of the metaphor of the territory as a palimpsest to an elementary, descriptive mapping strategy is absolutely meaningful: dealing with space and form of territory (Gregotti, 1965), the atlas demonstrates the possibility of a mapping strategy which pertains to a very specific disciplinary field, that is to say, that morphological approach mainly cultivated by Italian scholars (Caniggia, 1976; Muratori, 1960). The atlas describes the morphological evolution as both material (a canal becoming a street, a building which is expanded, etc.) and immaterial transformations (changes in the property boundaries). This emerging double dimension of palimpsest-as both a space and a cartography-is the topic of Corboz's contribution to the atlas, "Le Dessous des Cartes" (Corboz 1993, 4-7), while the one by Léveillé accurately explains the whole methodology of the atlas (Léveillé 1993, pp. 9-11).

While the prototype of the Geneva Atlas plays an important role in translating the notion of palimpsest as a new paradigm for an operational mapping, its impact serves as evidence that cartography is not only a tool for analysis or description but also for planning and governance. Indeed, the 'palimpsest atlas' has not only been definitively integrated into design and planning practices, but it has also become the prime authoritative tool of Canton Geneva in the field of architectural and landscape heritage policy. Regarding the latter, it is important to point out that the same atlas authors have critically distanced themselves from this application as a normative tool, as the original, historical, and critical objective of the atlas was certainly not to 'celebrate' permanent and persistent structures by labelling them as heritage, nor to consider 'erasure' as destruction. According to Corboz, erasing is a legitimate 'writing action.'

\section{The Territorial Palimpsest: An Evolving Concept}

After the 'territorial turn,' nowadays, both territories and their representation have come to face new challenges: while territory is going through multiple transitionsenvironmental, social, and economic-, a new 'digital turn' has come to the fore as the main subject for territorial visualisation. More particularly, it is precisely the convergence of these two conditions that makes us believe that a critical and methodological update of Corboz's palimpsest could prove it still to be an operant and powerful theoretical frame.

On the one hand, emerging global issues-such as climate change, sources shortages, economic, and health crisis-are increasingly confronting territory with complex dynamics that are progressively replacing static and immanent structures. In this sense, the three categories of permanence, persistence, and disappearance can be seen as clues of today's discourses about material cycles, in dialogue with preservation, recycling, and demolition processes. Furthermore, it emerges an extended notion of time, that of dynamic, temporary, and cyclic, one that relates to both extremely short and longue durée processes. Within this framework, we can observe that current mapping productions call for the exploration of the interactions between spatial, social, and environmental processes through the prism of the temporal dimen- 

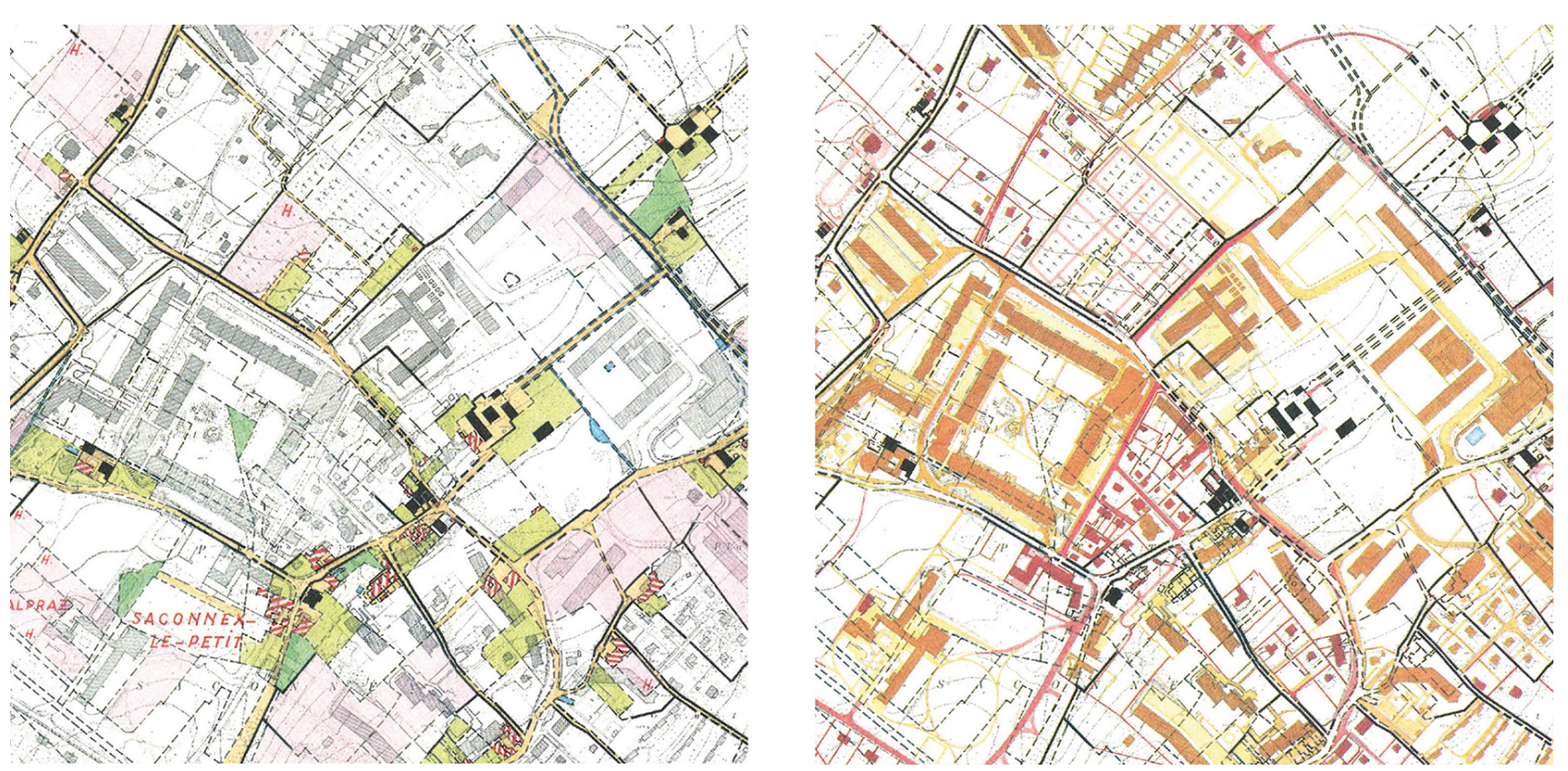

Figure 1. Atlas du Territoire Genevois. Left: Transcription of the Napoleonic cadastre to the 1991 plan. Synchronous reading of two states of the territory 170 years apart. Right: Comparison among the Napoleonic cadastre, the 1935-59 plan, and the 1991 plan. Formation/transformation of the territory 19th and 20th century; diachronic reading by attributing historical coordinates to each element of the built morphology (roads, parcel, building). Source: Service des Monuments et sites de la République et Canton de Genève (Léveillé et al., 1993).

sion, without necessarily considering the palimpsest theory and benefiting from its epistemological implications. After the deliberately 'reductive' approach of the Geneva atlas-dealing with complexity through a strong reduction of categories and elements-we think that the concept of 'territory as palimpsest' deserves to pass through a new process of extension and hybridization, so as not to exclude the possibility of being able to make new relevant reductions.

On the other hand, if since the 90s the multiple powers-internal and external-of maps were acutely unveiled (Harley, 1989; Wood, 1992), meanwhile, both the production of cartographies and the theoretical reflection on the same have been reinforced by the rapid evolution of new technologies of data sensing, collecting, sharing, and visualising. If we think that every two days more data is being produced than in all of history before 2003 (Kitchin, 2014), it becomes clear that such a large amount of information is imposing a further and unforeseen dimension on time: the so-called 'real-time,' a continuous and relentless flow of information that critically questions the agency of mapping as a necessary step of design operations. Moreover, new technologies such as 4D platforms coupled with point cloud modelling have introduced qualitatively different proceedings of understanding territorial and urban changes: They produce complex and incredibly precise images whose logics are only perceivable if the fourth dimension of time is added to those of space.

If referring to the main scope of this issue, these emerging technologies become key and meaningful in broadening and intensifying the potential of interpreting, shaping, and mapping our territories as constantly evolving processes, as transformative dynamics, and ultimately as both metamorphic and metabolic palimpsests. In other words, these emerging and rapidly evolving tools offer the conditions to update the palimpsest territorial analysis beyond its original morphological approach and towards one that reconstructs evolutionary processes on both the macroscopic and microscopic scale; one that operates an interdisciplinary investigation of hybrid processes intertwining geomorphological, social, mechanical, biological, climatic, and ecological dimensions with the multiple dimension of time. At the same time, if the act of considering space and forms as evolutionary processes through time allowed Corboz to criticize the conventional opposition between city and countryside, and to claim for the city-territory (Cavalieri \& Viganò, 2019; Tafuri, Piccinato, \& Quilici, 1962), nowadays the kaleidoscopic variety of temporalities that digital mapping deals with-the linear, the cyclic, and the instant time-creates extraordinary premises for a wide, interdisciplinary and democratic arena to debate categories and concepts of urban habitat.

Following this line of thinking, this thematic issue aims to first re-explore the metaphor of palimpsest as a methodological question in the light of a cartographical 'digital turn,' and then to reframe urban transformation within the renewed categories of both time and urban. Categories whose intertwining exemplifies the occasion for this thematic issue, that is rooted in the collaboration between the Habitat Research Centre and the Digital 
Humanities Laboratory, EPFL Lausanne. The former is a trans-disciplinary research platform that aims to explore the city-territory as a renewable resource and to produce visions, strategies, and projects on this primary and crucial topic; the latter, which initiated the Europe Time Machine network and shaped the Venice Time Machine as the first prototype, develops new computational approaches for rediscovering the past and anticipating the future. The fundamental hypothesis behind the need to digitalise materials such as historical archives, literature, cartographies, and ultimately cultures is that of putting forward a 'large' quantity of 'data' that, besides not being digital, has shaped the space we live in today (Kaplan, 2015). This twofold trajectory, also emphasized by the three commentaries in this thematic issue, reflects the main perspectives through which we intend to discuss the notion of the palimpsest: as an operant tool for renewed urban and historical analysis (Denny \& Waldheim, 2020), as a means for experimental design operations (Viganò, 2020), and as a 'horizon of reference' for re-orienting big data-based analysis (Kaplan \& di Lenardo, 2020).

Within such a binomial contextualisation, this issue attempts to reveal the multiple and possible applications of the palimpsest as a tool of both representation and historical interpretation that allows one to codify the present and thus to frame the future out of the restrictions of a prescriptive approach. A tool that goes beyond mainstream tendencies and that rather seeks to track down the weak signs, that sort of underneath spatial and cultural geographies that become the starting point for a specific type of project.

\section{Acknowledgments}

We would like to thank Swissuniversities-Promoting Exchanges among Swiss Doctoral Programs for funding the PhD Seminar "Habitats in Time. Mapping Palimpsest Horizons" we organized at EPFL, in December 2018 (Elena Cogato Lanza, EPFL Lausanne; Laurent Matthey and Serena Vanbutsele, UNIGE Geneva; Chiara Cavalieri, UCLouvain), and for supporting this thematic issue. The seminar was hosted by EDAR "Architecture and Sciences of the City" Doctoral Program (EPFL Doctoral School, EDOC). As this issue originates from that seminar, we would like to thank all PhD students who attended the seminar, in addition to all the authors of our articles and commentaries.

\section{Conflict of Interests}

The authors declare no conflict of interests.

\section{References}

Caniggia, G. (1976). Le strutture dello spazio antropico [The structures of anthropic space]. Florence: Uniedit.
Cavalieri, C., \& Viganò, P. (Eds.). (2019). The horizontal metropolis: A radical project. Zurich: Parkbooks.

Corboz, A. (1983). Le territoire comme palimpseste [The land as palimpsest]. Diogène, 121, 14-35.

Corboz, A. (1993). Le dessous des cartes [The underneath of maps]. In A. Léveillé, Y. Cassani, M.-P. Mayor (Eds.), Atlas du Territoire Genevois. Permanences et modifications cadastrales aux xix et $x x$ siècles [Atlas of the Geneva territory: Permanences and cadastral changes in the 19th and 20th centuries] (pp. 4-7). Geneva: Département des travaux publics du canton de Genève, Service des monuments et des sites, Centre de recherche sur la rénovation urbaine.

Denny, P., \& Waldheim, C. (2020). Reconsidering Hilberseimer's Chicago. Urban Planning, 5(2), 243-248.

Genette, G. (1982). Palimpsestes: La littérature au second degré [Palimpsests: The literature at the second degree]. Paris: Le Seuil.

Gregotti, V. (1965). The form of landscape. Edilizia Moderna, 87/88, 147-156.

Harley, J. B. (1989). Deconstructing the map. Cartographica, 26(2), 1-20.

Huet, B. (1986). L'architecture contre la ville [The architecture against the city]. AMC, 14, 10-13.

Kaplan, F. (2015). A map for big data research in digital humanities. Frontiers in Digital Humanities, 2. https://doi.org/10.3389/fdigh.2015.00001

Kaplan, F., \& di Lenardo, I. (2020). The advent of the $4 d$ mirror world. Urban Planning, 5(2), 307-310.

Kitchin, R. (2014). Big data, new epistemologies and paradigm shifts. Big Data \& Society, 1(1), 1-12.

Léveillé, A. (1993). La forme du territoire [The form of territory]. In A. Léveillé, Y. Cassani, M.-P. Mayor (Eds.), Atlas du Territoire Genevois. Permanences et modifications cadastrales aux xix et xx siècles [Atlas of the Geneva territory: Permanences and cadastral changes in the 19th and 20th centuries] (pp. 9-11). Geneva: Département des travaux publics du canton de Genève, Service des monuments et des sites, Centre de recherche sur la rénovation urbaine.

Léveillé, A., Cassani, Y., \& Mayor, M.-P., (1993). Atlas du Territoire Genevois. Permanences et modifications cadastrales aux xix et $x x$ siècles [Atlas of the Geneva territory: Permanences and cadastral changes in the 19th and 20th centuries]. Geneva: Département des travaux publics du canton de Genève, Service des monuments et des sites, Centre de recherche sur la rénovation urbaine.

Marot, S. (2013). Envisioning hyperlandscapes. Harvard Design Magazine, 2013(Spring), 89-95.

Muratori, S. (1960). Studi per un'operante storia urbana di Venezia [Studies for an operant urban history of Venice]. Rome: La Libreria dello Stato.

Rossi, A. (1966). L'architettura della città [The architecture of the city]. Venice: Marsilio.

Rowe, C., \& Koetter, F. (1978). Collage city. Cambridge, MA: MIT Press.

Tafuri, M., Piccinato, G., \& Quilici, V. (1962). La città 
territorio: Verso una nuova dimensione [The cityterritory: Towards a new dimension]. Casabella Continuità, 270, 16-25.

Viganò, P. (2020). Palimpsest metaphor: Figures and spaces of the contemporary project. Urban Planning, 5(2), 167-171.

Wood, D. (1992). How maps work. Cartographica, 29(3/4), 66-74.

\section{About the Authors}

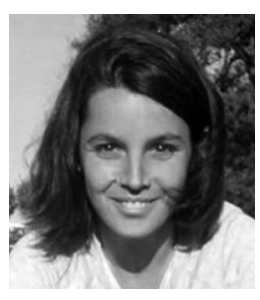

Chiara Cavalieri, Architect and PhD (Urbanism, IUAV, University of Venice), is Professor of Urbanism and Territorial Management at UCLouvain and member of the executive committee of the Habitat Research Center (HRC) at EPFL. Over the last years, she has taught and collaborated with a number of different international schools, including IUAV Venice, GSD Harvard, EPFLausanne, ITMO St. Petersburg, and ENSAP Lille.

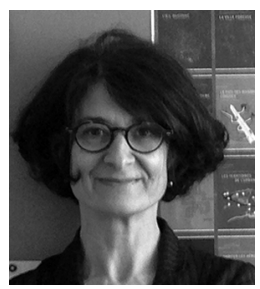

Elena Cogato Lanza, Architect (IUAV, University of Venice) and PhD (EPFL), is Senior Scientist at the Laboratory of Urbanism and Director of the Architecture and Sciences of the City Doctoral Program, École Polytechnique Fédérale de Lausanne. A member of several international publishing committees, she is associate publisher at MetisPresses (Geneva), where she directs the series vuesDensemble and vuesDensemble/Essai. Since 2015, she has been President of the Board of the Braillard Architectes Foundation in Geneva. 